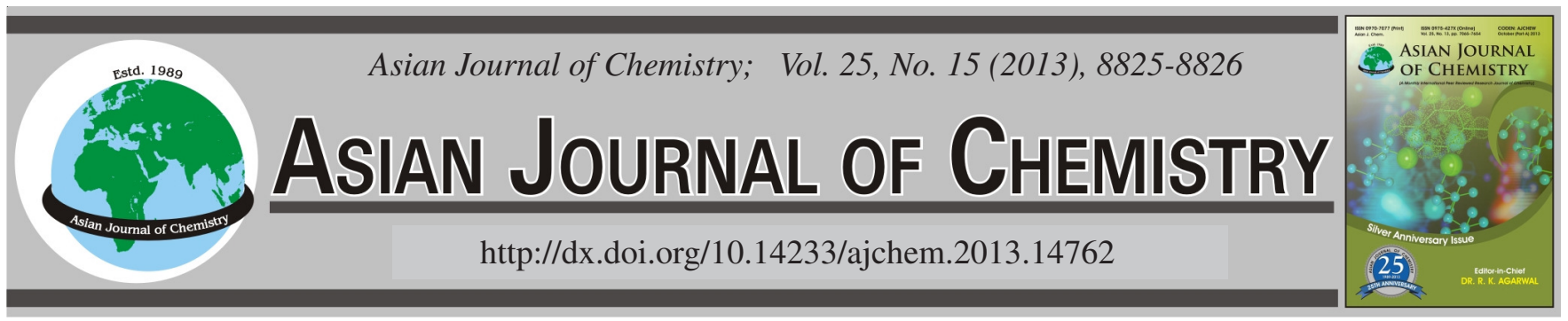

NOTE

\title{
Studies on the Flexible Epoxy Resin Curing Agent
}

\author{
X. WANG* and D.T. QI
}

CNPC Tubular Goods Research Institute, No. 32 Xi'an Dianzi Second Road, Xi'an 710065, Shaanxi Province, P.R. China

*Corresponding author: Tel./Fax: +86 29 88726389; Tel: +86 29 88726389; E-mail: npu18101@163.com; wangxi0215@hotmail.com

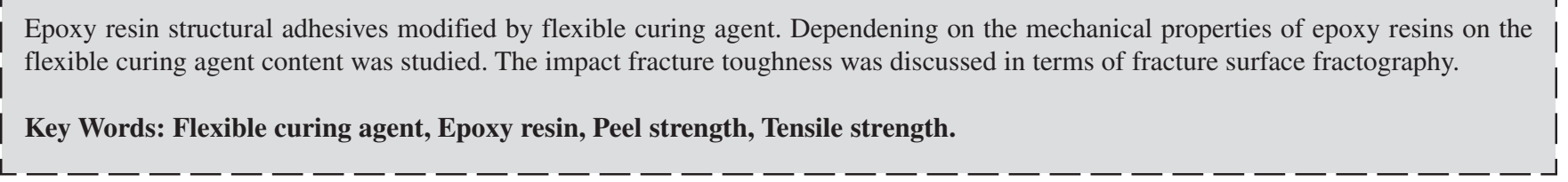

Textile adhesive is applied in the processing of yarn sizing, fabric paint textile dyeing and finishing, nonwovens processing, flocking fabric processing, textile coating finishing processing and garment processing ${ }^{1-4}$. On rainy days, when the humid environment or fabric with a water case, the bonding of textiles is hard, there is no report on special adhesive which may be use in humid condition.

Therefore, this article reports the flexible curing agent in epoxy adhesive, to explore the feasibility of formula scheme of fabric bonding with water and the variation of adhesive properties during processing.

Epoxy resin E-44, 810 underwater fast-curing agent, flexible curing agent and coupling agents: IQ-I550 were purchased from the market.

The addition of flexible curing agent can improve the flexibility of the adhesive. The 810 curing agent adding 20 wt. $\%$ and flexible curing agent take 5, 10, 15, 20 and 25 wt. $\%$ of the experiment.

It can be seen from the Fig. 1 and the Table- 1 that the adhesive tensile strength also increases with the increasing flexible curing agent content. However, more than $20 \mathrm{wt} \%$ the adhesive tensile strength do not increase and it maintain in a certain level. Therefore, the amount of flexible curing agent for epoxy resin is $20 \mathrm{wt} \%$.

The characteristic temperature of exothermic peak with a linear heating rate, the heating rate increasing the curing onset temperature and peak temperature increase. The move to the high temperature at the curing temperature range wider, which is due to an increase in heating rate, then $\mathrm{dH} / \mathrm{dt}$ is increases, the thermal effect produced per unit time increases, but the body to absorb the energy of shorter response lag more,

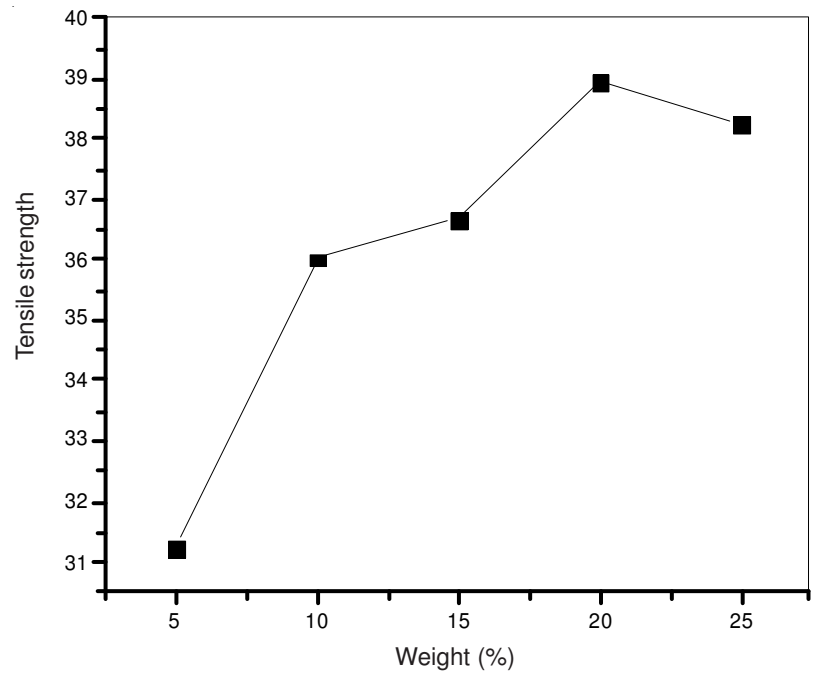

Fig. 1. Different quality of flexible curing agent on tensile strength

\begin{tabular}{lccccc} 
TABLE-1 & & \\
DIFFERENT QUALITY OF FLEXIBLE \\
CURING AGENT ON TENSILE STRENGTH \\
\hline Flexible curing agent (\%) & 5 & 10 & 15 & 20 & 25 \\
Peel strength (MPa) & 31.25 & 36.04 & 36.68 & 38.93 & 38.25 \\
\hline
\end{tabular}

so the characteristic temperature of exothermic peak corresponding increase in the curing reaction exothermic peak corresponding to the high temperature movement; generated due to thermal inertia, the greater the temperature difference.

Exothermic peak characteristic temperature curve with a heating rate of the different significant difference in the resin curing reaction is generally carried out at a constant temperature. In order to eliminate this effect can be the T-R push 
seeking a heating rate to $0{ }^{\circ} \mathrm{C} / \mathrm{min}$. As shown in Fig. 2, when the heating rate pushed to $0^{\circ} \mathrm{C} / \mathrm{min}$ curing process temperature predictive value of curing the initial temperature $\mathrm{Ti}=40.5^{\circ} \mathrm{C}$, curing peak temperature $\operatorname{Tr}=80.5^{\circ} \mathrm{C}$.

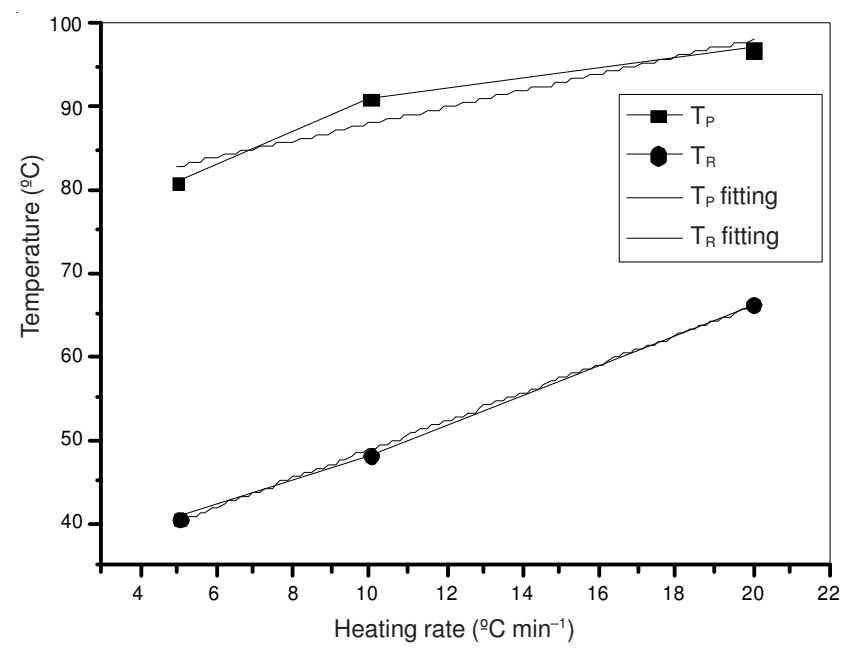

Fig. 2. Exothermic peak characteristic temperature and heating rate

Corresponding to the peel strength and flexible curing agent (Fig. 3), the peel strength along with the slow increase with the increase in the amount of flexible curing agent. Flexible curing agent maintain $15 \mathrm{wt}$. \%, the peel strength of the epoxy adhesive bonding fabric maximum, of $1.55 \mathrm{kN} / \mathrm{m}$, $18.3 \%$ more than which do not add the flexible curing agent. Flexible curing agent and epoxy resins with long carbon chains interspread with cross-linked network of the epoxy resin main chain, when the adhesive by peeling energy, can play the role of stress dispersion and withstand stress, adhesive fracture energy, which improved the fabric adhesive peel strength.

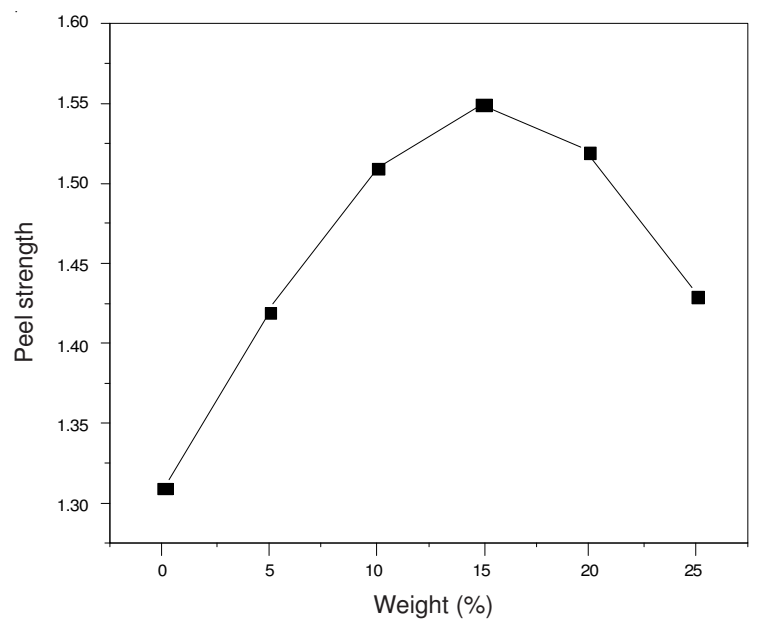

Fig. 3. Peel strength as flexible curing agent content
Corresponding to the peel strength and flexible curing agent (Fig. 4), the peel strength along with the slow increase with the increase in the amount of flexible curing agent. Flexible curing agent for epoxy resin $15 \mathrm{wt}$. \%, the peel strength of the epoxy adhesive bonding fabric maximum, of $1.49 \mathrm{kN} / \mathrm{m}$, $20.2 \%$ more than do not add the flexible curing agent. When the adhesive used in the water condition, the 810 curing agent can make the adhesive is still able to fabric bonding with flexible curing agent in water condition. When the adhesive by peeling energy, it can play the role of stress dispersion and withstand stress, which makes the fabric adhesive peel strength is still in the water environment is improved.

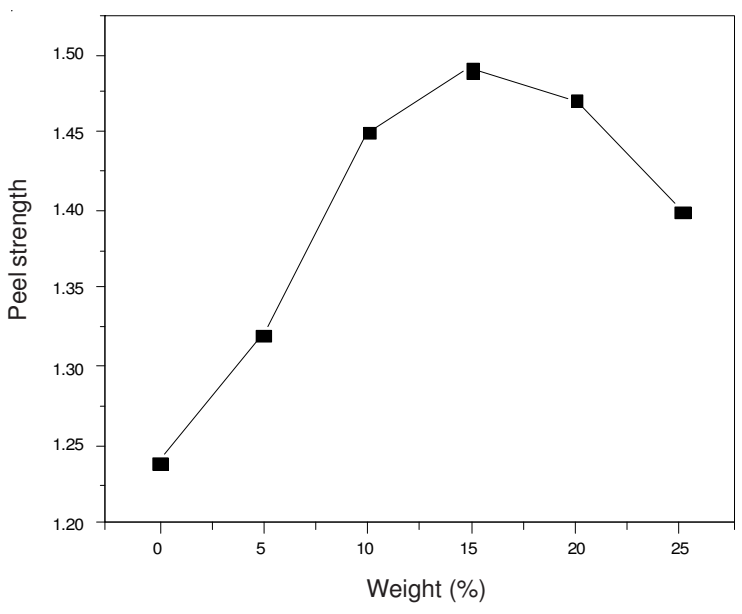

Fig. 4. Peel strength as flexible curing agent content

\section{Conclusion}

The experiment proved that the flexible curing agent modified epoxy resin adhesive with water fabric surface, quick and easy operation characteristics. The climatic conditions of simulated rain experiment results show that this new kind of flexible water-fabric adhesive. Under laboratory conditions, the fabric is completely immersed in water, fiber absorbent saturated bond strength up $1.49 \mathrm{kN} / \mathrm{m}$.

\section{REFERENCES}

1. A. Kannekens, J. Coated Fabrics, 7, 51 (1994).

2. G.R. Lomax, J. Coated Fabrics, 10, 91 (1984).

3. G.R. Lomax, J. Coated Fabrics, 15, 41 (1985).

4. Ye Qingxuan, Polyurethane Ind., 3 (1996). 